\title{
ENCONTRO COM A LINGUAGEM DO POVO HUNI KUIN: CURRÍCULO EM DEVIR
}

\author{
MEETING WITH A HUNI KUIN PEOPLE'S LANGUAGE: CURRICULUM \\ IN BECOMING
}

Valda Inês Fontenele Pessoa ${ }^{1}$

\section{RESUMO}

O artigo alinhava contribuições ao conceito de currículo do devir, veiculado em um artigo anterior. A metodologia pautou-se no levantamento da literatura pertinente à temática e a produção de currículos diferenciados, esboçados nas duas últimas décadas, veiculados em dissertações e teses originárias de Programas de Pós-Graduação do norte do Brasil. Resgata-se discussões acerca dos desenhos curriculares e articula-se a duas metáforas da linguagem Huni Kuin, oferecendo outras possibilidades que superem o cerceamento das propostas nacionais. A compreensão do conceito de currículo em devir está articulada à perspectiva dos estudos de Deleuze $(1988 ; 2003)$, no qual os sujeitos do processo educativo assumem eticamente o protagonismo das ações, embasados em estudos, diálogos e reflexões, sem a submissão a outros que não vivenciam a escola. Para Deleuze a arte seria o apogeu do processo de articulação da linguagem. O artista incumbe-se do processo de ressignificação dos signos, libertando-os das âncoras sociais que os aprisionam. O currículo do devir teria esse desenho, livre, polissêmico, aberto à criação de possibilidades. Duas metáforas da linguagem Huni Kuin são articuladas por conter um potencial explicativo capaz de esclarecer o conceito de currículo do devir: Yube (jibóia) e Kene ku (desenhos verdadeiros), revertendo a ordem predominante do desenho arbóreo que orienta os currículos.

\section{Palavras-Chave}

Linguagem. Indígena. Currículo. Devir. Metáfora.

\begin{abstract}
The article aligned contributions to the concept of curriculum of becoming, conveyed in an earlier article. The methodology was based on a survey of the pertinent literature to the thematic and the production of differentiated curricula, outlined in the last two decades, published in dissertations and theses originated from Post Graduation Programs in northern Brazil. It rescues discussions about curricula designs and articulates two metaphors of the Huni Kuin language, offering other possibilities that go beyond the curtailment of national proposals. The understanding of the concept of curriculum in becoming is articulated with the perspective of studies by Deleuze (1988; 2003), in which the subjects of the educational process ethically assume the leading role of actions, based on studies, dialogues and reflections, without the submission to others who don't experience school. To Deleuze art would be the apogee of the process of articulating language. The artist undertakes the process of resignification of signs, freeing them from the social anchors that imprison them. The curriculum of becoming would have this free, polysemic design, open to the creation of possibilities. Two Huni Kuin language metaphors are articulated because they contain an explanatory potential that can clarify the concept of curriculum of becoming: Yube (boa constrictor) and Kene $k u$ (true drawings), reversing the predominant order of tree design that guides curricula.
\end{abstract}

\section{KeYwORDS}

Language. Indigenous. Curriculum. Becoming. Metaphor.

1 Doutora em Educação pela Pontifícia Universidade Católica de São Pulo, Professora do Programa de Pós-Graduação em Letras: Linguagem e Identidade, Universidade Federal do Acre 


\section{Palavras iniciais}

Nossa pretensão é alinhavar contribuições à compreensão de desenvolvimento curricular em devir, veiculado em um artigo anterior, publicado por Pinheiro e Pessoa (2018). Nesse sentido, tornando a intenção mais explícita, o nosso intuito é responder como a lógica da linguagem do povo Kaxinawá pode contribuir metodologicamente para tornar possível a compreensão de caminhos de desenvolvimento de currículos abertos, em constante vir a ser. Assim, esse artigo é fruto de parte de uma pesquisa bibliográfica em andamento que tem como propósito subsidiar a construção de ideias que favoreçam o desenvolvimento de currículos em devir nas ações formativas de professore(a)s. Até a altura desta escrita, a geografia, as entradas e saídas de desenvolvimento da pesquisa (metodologia da pesquisa), pautou-se no levantamento da literatura pertinente à temática e a produção de currículos diferenciados, esboçados nas duas últimas décadas, veiculados em dissertações e teses originários de Programas de Pós-Graduação de instituições do norte brasileiro, especificamente do estado do Acre.

Para tanto, regatamos do campo dos estudos curriculares das últimas décadas, principalmente após a virada linguística, as consistentes discussões acerca dos desenhos curriculares e das possibilidades vivenciadas em diferentes escolas, oferecendo alternativas que superem a monotonia das repetições centradas nas propostas nacionais, iniciadas na década de noventa, inibidoras do potencial de criação dos sujeitos que vivenciam o cotidiano das organizações escolares. A ideia é trabalhar na perspectivas de currículos localizados, indo ao encontro do que Gallo (2002) denomina de educação menor. Segundo ele.

\footnotetext{
se há uma literatura menor, por que não pensarmos numa educação menor? Para aquém e para além de uma educação maior, aquela das políticas, dos ministérios e secretarias, dos gabinetes, há também uma educação menor, da sala de aula, do cotidiano de professores e alunos (GALLO, 2002, p. 169).
}

Assim, estamos nos colocando distantes do pensamento, moldes curriculares imperialistas e impeditivos da polissemia dos sentidos e que se cercam de linguagens isolacionistas da eficácia, da disciplinarização, da avaliação em larga escala e das técnicas fechada, homogeneizadoras de intenções (PESSOA, 2018). O pensamento da racionalidade técnica, sustentado pela crença da objetividade, tem inviabilizado outras perspectivas, outros saberes e outras formas de abordagens mais próximas dos grupos para os quais os currículos se destinam. Diferentemente dessa perspectiva racionalista, estamos compreendendo o conceito de currículo em devir no horizonte dos estudos de Deleuze (1988; 1998²; 2003), para o qual os sujeitos do processo educativo (alunos e professores) assumem eticamente o protagonismo das ações, embasados em estudos, diálogos e reflexões, sem a dependência e submissão a outros sujeitos que não vivenciam o cotidiano escolar.

Esse filósofo francês que viveu no século XX, ao estudar a literatura de Marcel Proust, desenvolve um debate que contribui com a construção do conceito do currículo em devir. Embora a atenção central nessas três obras não fosse o campo da educação, suas discussões fazem interface com a temática do processo de desenvolvimento curricular que se estabelece por meio da linguagem. Para ele, devir é a substância do desejo e desejar é atravessar devires. Por esse horizonte Zourabichvili (2004, p. 25) explicita com propriedade a compreensão de Deleuze, explicando a lógica

2 Esta edição digital dos Diálogos é uma revisão da versão “scaneada” que está disponível na web. (Nota do Revisor da Digitalização). 
de funcionamento do devir. "Todo devir forma um "bloco", em outras palavras, o encontro ou a relação de dois termos heterogêneos que se "desterritorializam" mutuamente. Não se abandona o que se é para devir outra coisa (imitação, identificação), mas uma outra forma de viver e de sentir". $\mathrm{Na}$ relação resulta um coeficiente de alteridade. Se estabelecermos a equação currículo nacional prescrito $\rightarrow$ professor $(a) \rightarrow$ aluno(a), acomodada nos termos de Deleuze, poderíamos entender o currículo em devir da forma que segue: Currículo nacional prescrito (representado por X) em relação com o(a) professor(a) (representado por Y); da relação mobilizariam-se quatro termos e não dois como resultado da equação. A relação de $\mathrm{X}$ com $\mathrm{Y}$ torna-se $\mathrm{X} 1$, ao passo que $\mathrm{Y}$ tomado nessa relação com X, torna-se Y1. Da mesma forma, a relação do currículo nacional prescrito em acontecimento $^{3}$ na esfera do professor(a) (representado por X1) com o(a) aluno(a) (representado por A) resulta em A1. Ou seja, os dois devires formam dois blocos heterogêneos desterritorializados (currículo nacional prescrito e professor(a); currículo nacional prescrito em acontecimento pelo(a) professor(a) e aluno(a) que resultam em coeficientes de alteridade possibilitados pela linguagem.

Para Deleuze a arte seria o mais alto grau, ou melhor, o apogeu do processo de articulação da linguagem. O artista incumbe-se do processo de ressignificação dos signos, libertando-os das âncoras sociais que os aprisionam e que estão tão bem abordadas na obra deste autor. Em sua perspectiva, a arte liberta, constrói mundos, significados e possibilidades, a partir de repertórios diversos e extraídos da multiplicidade cultural que se absorve, se conectam, hibridizando-se em outros significados, em outras formas e potencialidades.

Deleuze (1998) ao refletir sobre as questões que lhe chegam prontas e que têm origem em outros, mesmo que cause interesse, afirma que reduz as possibilidades. Quando os questionamentos são fabricados externamente, pouco resta a dizer. Se não há a possibilidade da construção das suas próprias perguntas, a partir de elementos que emergem de todas as partes dos círculos de contato, subsiste pouquíssimo espaço para dizer, criar, inventar. Para ele "a arte de construir um problema é muito importante: inventa-se um problema, uma posição de problema, antes de se encontrar a solução” (DELEUZE, 1998, p. 9). Os devires

são geografia, são orientações, direções, entradas e saídas. Há um devir-mulher que não se confunde com as mulheres, com seu passado e seu futuro, e é preciso que as mulheres entrem nesse devir para sair de seu passado e de seu futuro, de sua história. Há um devir-revolucionário que não é a mesma coisa que o futuro da revolução, e que não passa inevitavelmente pelos militantes. Há um devir-filósofo que não tem nada a ver com a história da filosofia e passa, antes, por aqueles que a história da filosofia não consegue classificar. Devir é jamais imitar, nem fazer como, nem ajustar-se a um modelo, seja ele de justiça ou de verdade. Não há um termo de onde se parte, nem um ao qual se chega ou se deve chegar. Tampouco dois termos que se trocam. [...] Os devires não são fenômenos de imitação, nem de assimilação, mas de dupla captura, de evolução não paralela, núpcias entre dois reinos (DELEUZE, 1998, p 2-3).

Assim, o currículo em devir teria esse desenho, livre, polissêmico, aberto a questionamentos e a criação de possibilidades, em consonância com o repertório cultural dos protagonistas,

\footnotetext{
3 Esse termo está relacionado com o conceito de acontecimento disseminado por Deleuze. De acordo com o seu pensamento o acontecimento "é inseparavelmente o sentido das frases e o devir do mundo. É o que, do mundo, deixa-se envolver na linguagem e permite que funcione. Assim, o conceito de acontecimento é exposto na Lógica do sentido (ZOURABICHVILI, 2004, p. 7). Então não se perguntará qual o sentido de um acontecimento: o acontecimento é o próprio sentido. O acontecimento pertence essencialmente à linguagem, mantém uma relação essencial com a linguagem; mas a linguagem é o que se diz das coisas." (LS,34)
} 
que estão entre dois reinos, em potência diferenciadas, inquietos e incentivados a encontros que impulsionam ir à frente, a querer sempre mais. Mais saber, mais encontros, mais diálogo entre iguais e diferentes, para além das caixinhas dos saberes disciplinares que a modernidade impôs. $\mathrm{O}$ acontecimento ${ }^{4}$ escolar, com essa perspectiva curricular em devir, possibilitariam múltiplos saberes e múltiplas ações imprevisíveis, oxigenando a capacidade de se por a pensar e criar, em trânsito constante de processos de significação, criando caminhos não previstos, mas interconectado com as culturas dos participantes do processo educativo (COSTA, 2011; MOREIRA, 2011, 2011). Com esse panorama o didatismo estéril, o proselitismo pedagógico e a burocratização mental estariam alijados do processo.

Por essa concepção, não criamos e implementamos currículos sem fazer parte deles. Para explicar essa afirmação, parafraseando o pensamento de Deleuze a respeito do trabalho pleno, podemos afirmar que ao criar e implementar currículos em devires os sujeitos passam por um quadro de solidão absoluta, mas que esta solidão é repleta de povoamento nos quais os encontros se dão por completo. "É do fundo dessa solidão que se pode fazer qualquer encontro. Encontram-se pessoas (e às vezes sem as conhecer nem jamais tê-las visto), mas também movimentos, ideias, acontecimentos, entidades" (DELEUZE, 1998, p. 6).

O currículo em devir passa por esse trânsito. Acontece em ziguezague, que passa entre dois em distinta diferença de potência, tornando-se devires em dupla captura. Devires, como exposto anteriormente, "não é um termo que se torna outro, mas cada um encontra o outro, um único devir que não é comum aos dois, já que eles não têm nada a ver um com o outro, mas que está entre os dois, que tem sua própria direção" (DELEUZE, 1998, p. 6). Nessa conversa sobre devires, esse pensador toma como exemplificação os acontecimentos que envolvem a vespa e a orquídea, esclarecendo de forma palpável a sua concepção, como segue na transcrição:

A orquídea parece formar uma imagem de vespa, mas, na verdade, há um devir-vespa da orquídea, um devir-orquídea da vespa, uma dupla captura pois "o que" cada um se torna não muda menos do que "aquele" que se torna. A vespa torna-se parte do aparelho reprodutor da orquídea, ao mesmo tempo em que a orquídea torna-se órgão sexual para a vespa. Um único e mesmo devir, um único bloco de devir, ou, como diz Rémy Chauvin, uma "evolução a-paralela de dois seres que não têm absolutamente nada a ver um com o outro (DELEUZE, 1998, p. 3).

É nessa perspectiva que acontece a dupla captura no currículo. O que está na proposta inicial do currículo, elaborada por outros e externamente à escola, não está no(a) professor(a) nem no(a) aluno(a); como o(a) aluno(a) e o(a) professor(a) não estão no currículo, mesmo que haja troca, se dá entre, fora dos dois e que toma diferentes direções a partir do encontro.

Encontrar é achar, é capturar, é roubar, mas não há método para achar, nada além de uma longa preparação. Roubar é o contrário de plagiar, de copiar, de imitar ou de fazer como. A captura é sempre uma dupla-captura, o roubo, um duplo-roubo, e é isso que faz, não algo de mútuo, mas um bloco assimétrico, uma evolução a-paralela, núpcias, sempre "fora" e "entre (DELEUZE, 1998, p. 6-7).

É nessa perspectiva, que há encontro com a sabedoria da linguagem do povo Kaxinawá, possibilitando contribuições que nos ajudam a tornar mais consistente a ideia de currículo em devir.

4 Ver o conceito de acontecimento na nota de rodapé número 2. 


\section{O ENCONTRO COM A LINGUAGEM INDÍGENA}

Em artigo apresentado em comunicação oral em 2007 e publicado em 2010, Ferreira descreve o processo de pesquisa participante em que expõe a construção do Projeto Político Pedagógico em conjunto com o povo Kaxinawá. O artigo desse autor é parte integrante da pesquisa por ele desenvolvida no Programa de Pós-graduação em Antropologia Social da Universidade Federal do Paraná para a obtenção do título de mestre.

É importante salientar, que dentre a população indígena do Acre, esse povo é o que tem o maior número de professores, como também, é o que apresenta o maior percentual de escolas de formação básica. Dessa forma, a recorrência de profissionais da Secretaria de Estado de Educação - SEE e de Organização Não Governamental - ONG, acompanhando e orientando o trabalho desenvolvido por essas escolas não é pequeno. Paulo Roberto Ferreira é um desses profissionais, que motivado por sua trajetória de trabalho, resolve investigar mais detidamente o que vinha desenvolvendo. Assim, sua dissertação trata do esforço em curso do povo Kaxinawá para reposicionar suas escolas em outros patamares, articulando-as aos seus ideais e a partir das relações que estabelecem intra e interetnicamente. A não resignação às repetições veiculadas pelas orientações pedagógicas da SEE, os impulsionavam, parecendo ser mais um aspecto do devir indígena, característico do seu modo de pensamento.

O recorte empírico que Ferreira (2010) estabelece para a sua análise, constituinte do seu trabalho acadêmico, está centrado nas oficinas pedagógicas realizadas com os Huni Kuin, realizadas entre os anos de 2004 a 2007 e que a partir delas, mobilizaram debates, conversas, entrevistas e convivência prolongada com essa comunidade indígena.

A partir dos debates, oficinas e entrevistas desenvolvidas em terras do povo Kaxinawá sobre suas concepções de escola e conhecimento, nas quais participaram anciãos, mulheres, lideranças masculinas e femininas, agentes indígenas agro-florestais e de saúde, pajés, líderes de canto e jovens, foram extraídas quatro metáforas contidas em suas linguagens, que são representativas das lógicas de pensamento que empreendem em suas imaginações: nukun yura; nixi pae; yube (jibóia) e kene ku, das quais explicitaremos as duas últimas, por conterem um potencial explicativo capaz de tornar o conceito de currículo em devir mais palpável e passível de compreensão.

Antes de passarmos a essa explicitação, é oportuno expor o contexto e condições estabelecidas para a realização das oficinas. O autor da pesquisa, como indigenista e técnico em educação da Coordenação de Educação Escolar Indígena - C.E.E.I., vinculada à Secretaria de Educação do Estado do Acre, participou no período de 2004 a 2007 de três oficinas como um dos protagonistas, representando essa secretaria estatal. Antes desse período, a prática de orientação da educação indígena realizada pela C.E.E.I., era desenvolvida por meio de acompanhamento pedagógico esporádicos, em visitas individuais aos professores das escolas nas aldeias e em cursos de formação de professores em município próximo ou pela Comissão Pró-Índio-AC.

A orientação dessas duas unidades operadoras da educação indígena no Acre, era marcada pelo acirramento de ideias opostas e difíceis de atingir o consenso. Do lado oficial, Secretaria de Estado de Educação, as práticas eram assinaladas por uma lógica homogeneizante e determinista e pelo lado da sociedade civil (CPI/AC), observava-se a intenção do assessoramento compartilhado, na defesa dos projetos indígenas na escola. Segundo Ferreira (2010a), após longos embates e 
o afunilamento das ideias dessas duas instituições, a C.E.E.I. passou a desenvolver as suas ações pedagógicas com especial atenção aos seguintes preceitos: interculturalidade; bilinguismo e autonomia das comunidades nas decisões acerca de seus projetos escolares.

Assim, no ano de 2004 de forma inédita e imersão prolongada dos técnicos educacionais da C.E.E.I, juntamente com professores e parentes Huni Kui de três terras indígenas vizinhas, reuniram-se em torno de temáticas da primeira oficina pedagógica em que os protagonistas eram os Kaxinawá, indigenistas educadores, lideranças, pajés, etc. para discutirem e definirem prioridades para construírem o Projeto Político Pedagógico de suas escolas.

Após essa primeira oficina, outras se sucederam, tendo como principal metodologia de trabalho a dinâmica empreendida no marco inicial de 2004. Assim, dessas oficinas surgiram as metáforas da linguagem indígena que vêm norteando os caminhos de desenvolvimento curricular das escolas do povo Kaxinawá, das quais, duas são explicitadas, a saber: Yube (jibóia) "ensina o que contém o mundo na potencialidade de seus desenhos. O desenho da cobra contém o mundo. Cada mancha na sua pele pode se abrir e mostrar a porta para entrar em novas formas. Tem-se uma jibóia que ensina, e desenhos no seu corpo que abrem as portas para novas formas no mundo" (p. 170).

Já a metáfora Kene ku significa desenhos verdadeiros. São aqueles que sugerem "uma multiplicidade de caminhos. Teríamos, então, ao invés de uma percepção imaginativa, teríamos uma imaginação perceptiva”. Esclarecem ainda que pelas manchas na pele da cobra se pode vislumbrar possibilidades, ou seja, "assim que um padrão é identificado, outro dá continuidade; ele encerra-se independente da margem. Quem vê deve ter a capacidade de projetar, de imaginar para perceber a sua continuidade...” (p. 171). Como é possível observar, essas duas metáforas da linguagem kaxinawá agregam explicações para compreender o que estamos entendendo por desenvolvimento curricular em devir, diferentemente da perspectiva arbórea.

\section{Desenhos CURriculares: ARbóreo, rizomático e da JibóIA}

Desenho arbóreo

O desenho da árvore tem orientado secularmente a imagem do ato de pensar/fazer ciência/ aprender/organizar currículos. A lógica de pensamento dos sujeitos imita a constituição da árvore, buscando nas raízes e/ou nos tempos remotos a chave para os desdobramentos dos conhecimentos, sua sequência e sustentação, cultivando dessa forma, o mito da origem, do nascimento das coisas e dos seres em geral. Esse arquétipo submete, mesmo que de forma idealista, o pensamento a desdobramentos graduados que guardam entre si relações de causa e efeito conduzindo-o a direcionamentos, ora do geral ao particular ou vice-versa, ancorando-o em terrenos envolto de "vontade de verdade"

Nessa perspectiva, é possível definir previamente a metodologia de pensamento e de ação, cercando de certezas os poucos caminhos a serem percorridos, mas que por outro lado, deixa em plano secundário os sujeitos e os devires que esses constroem. Essa epistemologia categoriza e organiza em hierarquia os conhecimentos, dividindo-os em compartimentos a partir de especificidades racionalizadas para enquadrá-lo em experimentos. A “experimentação" acontece a partir de um roteiro aprioristicamente definido, com larga margem para a reprodução do mesmo, uma vez que esse a priori dificulta outras possibilidades, outros caminhos e outros encontros.

5 “Conceito de Nietzsche, que levou ao método científico e à autonomização das ciências" (GALLO, 2004, p. 108). 
No modelo arbóreo, o conhecimento da humanidade é geografado a partir das partes que compõem a árvore. $\mathrm{O}$ mito da origem ou do começo de tudo está representado por suas raízes. $\mathrm{O}$ tronco robusto indica a filosofia; os galhos apontam as diferentes ciências e as ramificações revelam as especialidades, resultantes da absoluta compartimentalização produzida pela própria ciência, por decorrência do crescimento dos saberes e pela impossibilidade de dominá-los com profundidade. Nesse mapa é determinante o olhar hierarquizado, sendo a relação entre esses saberes pré-definidas, norteando da mesma forma as restritas possibilidades de caminhos para a busca de outros conhecimentos.

A convivência comunicativa entre os campos do saber só é aceita, se observada a hierarquia. O itinerário relacional entre galhos do saber só é permitido se atender ao percurso previamente definido. Como esse desenho orientador está sedimentado na lógica básica de orientar o processo de construção do conhecimento, finda redundando o nosso próprio modo de pensamento.

Predominantemente os currículos disciplinares são moldados por esse arquétipo. A epistemologia arbórea influenciou a ciência moderna e nessa seara, a Pedagogia encontrou terreno fértil para atender a sua vontade de constituir-se ciência, trazendo reflexos contundentes para a organização do trabalho escolar. Nesse sentido Gallo afirma que o

\begin{abstract}
modelo arbóreo ou radicular de capitalização do conhecimento científico serviu muito bem de planta para a fixação dos currículos escolares. A especialização dos saberes permitiu a especialização dos professores, do material didático e do espaço pedagógico, A fragmentação dos saberes permitiu o fracionamento do tempo escolar em aulas estanques. E tudo isso possibilitou que o processo pedagógico pudesse passar pelo crivo de um rígido controle, que pôde, por sua vez, dar à Pedagogia a ilusão de que logrou êxito em seu afã de constituir-se como ciência. No currículo disciplinar tudo pode ser controlado: o que o aluno aprende, como aprende, com que velocidade o processo acontece e assim por diante. Tudo pode ser avaliado: o desempenho do aluno, a "produtividade" do professor, a eficácia dos materiais didáticos etc. Da mesma forma, todo o processo pode ser metrificado e o desempenho do aluno traduzido numa nota, às vezes com requinte de fragmentação, incorporados no número de casas decimais (GALLO, 2004, p. 108).
\end{abstract}

Nesses moldes, como bem descreve a citação, a organização da escola e em especial o currículo disciplinar, funcionam em consonância com os preceitos da Pedagogia moderna, mas dizer que possibilita devires aos sujeitos que delas participam, em toda a sua potência não somos otimistas. No Brasil, estudiosos do campo da educação incomodados com o esgotamento dessa forma de organização da escola e de seus currículos disciplinares, começaram a adentrar na possibilidade de outras organizações curriculares. Com a evidente incapacidade dos alunos em estabelecerem nexos entre os saberes que constituem o currículo compartimentado, na década de noventa são ensaiados novos desenhos, vislumbrando superar a fragilidade dos alunos da educação básica. No campo acadêmico, após a redemocratização do país, as discussões se adensaram em torno dos currículos, passando-se a falar em multidisciplinaridade, pluridisciplinaridade, intercisciplinaridade e transdisciplinaridade em busca de caminhos que possibilitassem maiores interconexões entre as diferentes áreas disciplinares representadas nos currículos da educação básica.

No campo das políticas públicas brasileiras, após a aprovação da Lei de Diretrizes e Bases da educação nacional - LDB/1996, o Ministério da Educação - MEC, na tentativa de minimizar a fragmentação da organização do currículo do ensino fundamental e médio, importa as ideias da 
experiência espanhola ${ }^{6}$ para viabilizar os Parâmetros Curriculares Nacionais, publicados a partir de 1998. Essas orientações ao serem constituídas e disseminadas em todo o território nacional, trazem anexa o conjunto de "temas transversais" que seriam explorados articuladamente em sala de aula por cada disciplina, conectados aos conteúdos prescritos. No entanto, com o passar das novas gestões, foram desfalecendo até desaparecer por completo na última versão da Base Nacional Curricular Comum, aprovada recentemente. Essa foi uma política educacional que tentou viabilizar a interdisciplinaridade, mesmo mantendo em seu arcabouço, o modelo arbóreo de organização curricular.

Se tivesse tido continuidade, teríamos avançado em termos da diminuição da fragmentação disciplinar? Para Gallo (2004), sejam quais tenham sido as experiências, (interdisciplinar, pluridisciplinar ou transdisciplinar) o que tem ficado demonstrado é que o núcleo organizador do currículo continua sendo a perspectiva disciplinar. $\mathrm{Na}$ superfície, aparentam significar progressos pedagógicos, mas na realidade, têm afigurado ser o que não são, garantindo um contínuo de perpetuação da concepção do mapa dos saberes, orientado pela metáfora da árvore, que organiza por sua vez, o currículo disciplinar.

Há quase duas décadas, Silvio Gallo, filósofo da educação brasileira, vem trabalhando a concepção de transversalidade, amparado por Michel Foucault, Gilles Deleuze e Félix Guattari, inspirado pela metáfora do rizoma que esses dois últimos apresentam em suas obras para comentar as inúmeras e imprevisíveis ordens que possibilitam o pensamento e a criatividade, em contraposição ao desenho arbóreo.

\section{Desenho rizomático}

Diferentemente das árvores ou de suas raízes, o rizoma conecta um ponto qualquer com outro ponto qualquer, e cada um de seus traços não remete necessariamente a traços de mesma natureza, ele põe em jogo regimes designos muito diferentes, inclusive estados de não-signos. O rizoma não se deixa reduzir nem ao Uno nem ao múltiplo... Ele não é feito de unidades, mas de dimensões, ou antes, de direções movediças. Não tem começo nem fim, mas sempre um meio, pelo qual ele cresce e transborda. Ele constitui multiplicidades (MP, 31) (ZOURABICHVILE, 2004, p. 51-52).

O rizoma é um termo extraído da botânica. É um tipo de raiz de planta que fica geralmente abaixo da superfície da terra, podendo também ser aérea, dedicada a realizar trocas indistinguíveis, com o solo circundante. Se contrapõe à raiz arborescente, estratificada. Diferentemente desta, é uma rede móvel de caules, fluxos, redemoinhos, transversal, sem começo, nem fim, passíveis de entradas e saídas de qualquer lado, O seu desenho, diferentemente do desenho da árvore não expressa hierarquia. A conexão é aleatória e contingencial. É um sistema de passagens, constituído de atalhos e desvios que se encontram imprevisivelmente, mas nunca em vias diretas e retas. Um rizoma

não começa nem conclui, ele se encontra sempre no meio, entre as coisas, inter-ser, intermezzo. A árvore impõe o verbo "ser" mas o rizoma tem como tecido a conjunção “e...e...e...”" Há nessa conjunção força suficiente para sacudir e desenraizar o verbo ser. [...] Entre as coisas não designa uma correlação localizável que vai de uma para outra e reciprocamente, mas uma direção perpendicular, um movimento transversal que as carrega

6 Segundo Gallo (2004), a experiência espanhola, a qual serviu de parâmetro para a formatação da política brasileira, foi arrojada ao situar os temas de sua proposta voltados para o cotidiano e estes, por sua vez, centrais para a organização do currículo, de modo a fazer com que as disciplinas fossem articuladas em torno deles. 
uma e outra, riacho sem início nem fim, que rói as margens e adquire velocidade no meio (DELUZE e GUATTARI, apud RIBEIRO, 2016, p. 71).

Também com as âncora fincada em Zourabichvile (2004), podemos dizer que o rizoma representa um dos mais destacados conceitos da obra de Deleuze e Guattari. É demonstrativo de um novo desenho determinado a combater o desenho da árvore do conhecimento, que secularmente vem ordenando o ato de pensar e encaminha aos seus desdobramentos. Utilizam a metáfora do rizoma para indicar a inexistência de ponto de origem, de ordem ou de entrada inicial definida a comandar o pensamento. Os avanços significativos de ideias, pensamentos se fazem por bifurcações, por encontros imprevisíveis que favorecem ângulos de visão ainda não vistos, ou seja, inéditos. Nesse aspecto, o rizoma é um antimétodo, em que o seu rigor centra-se na criação e não na repetição encadeada pela burocratização do método, enxergando-os como muralhas impeditivas de visões inéditas. Tudo permite, em nome da criação. Desacreditam em caminhos retos e previamente definidos para o desenvolvimento do pensamento. Assim, a metáfora do rizoma é o método do antimétodo, que remete para a multiplicidade "e seus "princípios" constitutivos são regras de prudência a respeito de todo vestígio ou de toda reintrodução da árvore e do Uno no pensamento" (ZOURABICHVILE, 2004, p. 53).

Dessa forma, se concebermos o mapa dos saberes como um grande rizoma, sem início sem fim e sem hierarquia, nos deixaremos livres para experimentar infinitas possibilidades de trânsito entre os saberes e o pensamento funcionando por essas vias imprevisíveis, também resultariam em desenvolvimento curricular em devir. É nessa perspectiva que estabelecemos aproximações com a linguagem e mapa de pensamento do povo kaxinawá para ajudar subverter a ordem da metáfora arbórea.

\section{Desenho da Jiboia}

Os indígenas despertam outras possibilidades de ver, pensar e compreender o seu mundo. As compreensões que fazem parte desse ensaio estão circunscritas aos Kaxinawá/Huni Kuin, habitantes da floresta tropical do estado do Acre. Este povo integra a família linguística Pano, que vive na atualidade, processos de resgate de suas tradições. Até onde pudemos perceber, vivenciam relações sociais bem democráticas.

Segundo Lagrou (1998), por longas décadas estudiosa da sociedade Kaxinawá, a formação de novas aldeias entre os Pano acontece sem conflitos e é recorrente entre eles. Essa separação harmônica reflete a orientação democrática que constitui essa comunidade. Qualquer líder familiar pode decidir, por livre e espontânea vontade, transferir-se para outra localidade com a finalidade de formar uma nova comunidade. O sucesso para a concretização da sua vontade, vai depender da sua habilidade em convencer outros parentes a acompanha-lo. Não há pressão coercitiva para a permanência na mesma aldeia. Nos termos de Lagrou (2007), é uma nuance forte da identidade desse povo, irritar-se diante de posturas castradoras de suas autonomias. Homens e mulheres definem onde e com quem devem morar. O único motivo que imprime uma certa coerção é o afetivo. Não aceitam viver longe dos seus mais próximos.

Os kaxinawá enxergam na jiboia (yube) a potencialidade da sabedoria para o alcance de possibilidades de abertura de portas que levam a caminhos de construção de infinitas ideias para pensar o mundo, pois acreditam que os desenhos da sua pele são indicadores das múltiplas entradas e saí- 
das para pensar. As manchas que se formam desordenadamente na pele dessa cobra, são desenhos verdadeiros (kene ku). No desenho da jiboia, encontra-se a representação que essa comunidade indígena encontrou para indicar a imagem labiríntica que orientam a maneira que pensam. Não há um caminho. Há sim, experimentação e uma multiplicidade de possibilidade a partir do que observam na cobra que ensina. Nesse sentido, no processo de pensamento que implementam seguem trilhas que possibilitam a imaginação perceptiva, ao invés de uma percepção imaginativa, ou seja, "assim que um padrão é identificado, outro dá continuidade; ele encerra-se independente das margens. Quem vê deve ter a capacidade de projetar, de imaginar para perceber a sua continuidade" (FERREIRA, 2010a, p. 171).

Da afirmação por eles evidenciada, que diz que "quem vê deve ter a capacidade de projetar, de imaginar para perceber a sua continuidade", a partir das trilhas que visualizam nos desenhos verdadeiros, constata-se uma proximidade com o mapa de saberes rizomáticos. Se este é uma rede móvel de caules, fluxos, redemoinhos, transversal, sem começo, nem fim, passíveis de entradas e saídas de qualquer lado, visualizamos na pele da jiboia essa mesma configuração. Há nas manchas uma rede interconectada que reiniciam, sem necessariamente ser o começo ou o final. Mostram-se caminhos cruzados que podem ser considerados pontos de encontros de devires, sem que um seja o mesmo do outro e que para cada um os devires se dão diferentemente.

A conexão é aleatória e contingencial. É um sistema de passagens, constituído de atalhos e desvios que se encontram imprevisivelmente, mas nunca em vias diretas e retas, os desenhos verdadeiros (Kene ku) guardam a mesma ideia. Se sua imagem é entrecruzada, pode representar encontros que se conectam com um ponto qualquer, com outro ponto qualquer, suas manchas remetem a diferentes tamanhos e formatos, sem começo e nem fim, se alastrando diferentemente por toda a extensão do corpo, não se deixando reduzir ao mesmo, uma vez que não se repetem, constituindo uma multiplicidade.

\section{Finalizando...}

Em busca dos encontros, nos termos de Deleuze, é que enxergamos as possibilidades dos currículos em devir. Aqueles que ao serem desenvolvidos nas salas de aula, entra em fuga, se desterritorializando da educação maior, dos grandes mapas, dos grandes projetos realizados em gabinetes e que se constitui nos grandes documentos curriculares prescritos. Fuga da macropolítica educacional, para adentrar na micropolítica da sala de aula, dos sujeitos, dos desejos, em fim, para possibilitar blocos de devires, pois é nela (sala de aula) que emerge a expressão das ações cotidianas de cada um.

As macropolíticas curriculares, traduzidas em parâmetros, diretrizes e mais atualmente, a base nacional curricular comum - BNCC, como o mapa arbóreo, estão sempre a nos dizer o que ensinar, como ensinar e a que resultados chegar, como uma grande máquina de controle, reduzindo encontros e impossibilitando desejos de saber, de conhecer, de caminhar por trilhas indefinidas, como as do rizoma e dos desenhos da jiboia. Entre essas duas imagens não há uma relação de causa e efeito, que vai de uma para a outra reciprocamente. São direcionamentos que ligam, se cruzam umas com outras, multiplicando-se possibilidades.

Como a formação docente é predominantemente baseada na lógica arbórea, que por sua vez encaminha a matriz de organização do trabalho pedagógico, uma vez que seus profissionais têm 
uma árvore em suas cabeças orientando o seu pensamento, talvez seja uma das motivações dos grandes conflitos que assistimos atualmente nas escolar. Como bem assinala Gallo, o exercício do poder gera resistência e a tentativa de controlar tudo, pode fugir a qualquer controle. Para finalizar, transcrevemos essa máxima que muito acreditamos:

\footnotetext{
Aprender está para o rato no labirinto, está para o cão que escava seu buraco; está para alguém que procura, mesmo que não saiba o que e para alguém que encontra, mesmo que seja algo que não tenha sido procurado. E, neste aspecto, a aprendizagem coloca-se para além de qualquer controle (GALLO, 2002).
}

\section{REFERÊNCIAS}

COSTA, M. V. Estudos culturais e educação. In. SILVEIRA, Rosa Maria Hessel. Cultura, poder e educação: um debate sobre estudos culturais em educação. 2. ed., Canoas, Ed. Ulbra, 2011.

DELEUZE, G. Diferença e repetição. Tradução de Luiz Orlandi e Roberto Machado. Rio de Janeiro, Graal, 1988.

DELEUZE, G.; PARNET, C. Diálogos. Tradução de Eloisa Araújo Ribeiro. São Paulo, Escuta, 1998.

DELEUZE, G. Proust e os signos. Tradução de Antônio Piquent e Roberto Machado. Rio de Janeiro, Forense Universitária, 2003.

FERREIRA, P. R. N. Terra alta e terra baixa, escolas para índios e escolas indígenas: "tudo não é igual". In: BISPO, S. C. M.; NASCIMENTO, F. L.; ISHII, R. A. (Orgs.). Anais do Simpósio Linguagens e identidades da/na Amazônia Sul/Ocidental (2007). Rio Branco: Edufac, 2010, p. 169-184.

FERREIRA, P. R. N. Na "remenda do céu com a terra" escolas diferenciadas não são Huni Kui. Dissertação de mestrado. Programa de Pós-Graduação em Antropologia Social. Universidade Federal do Paraná, Curitiba, 2010a.

GALLO, S. Transversalidade e formação de professores. In. RIVERO, C. M. L.; GALLO, S. (Orgs.). A formação de professores na sociedade do conhecimento. Bauru-SP: Edusc, 2004.

GALLO, S. Em torno de uma educação menor. Educação e Realidade, n. 27(2), 2002, p.169-178.

LAGROU, E. Caminhos, duplos e corpos: uma abordagem perspectivista da identidade e alteridade entre os Kaxinawá. Universidade de São Paulo - USP. Tese de doutorado. São Paulo, 1998.

LAGROU, E. A fluidez da forma: alteridade e agência em uma sociedade amazônica (Kaxinawá, Acre). Rio de Janeiro: Topbook, 2007.

MOREIRA, A. F. B. Currículo e estudos culturais: tensões e desafios em torno das identidades. In. SILVEIRA, R. M. H. Cultura, poder e educação: um debate sobre estudos culturais em educação. 2. ed., Canoas, Ed. Ulbra, 2011.

PESSOA, V. I. F. Currículo sitiado: pluralidade negada. In: PESSOA, V. I. F.; SANTOS, Z. G. C. (Orgs.). Identidades: culturas, currículos e margens. Curitiba: CRV, 2018.

RIBEIRO, C. R. O agenciamento Deleuze-Guattari: considerações sobre método de pesquisa e formação de pesquisadores em educação. Revista Unisinos - Educação, v. 20, n. 1, jan./abr., 2016. disponível em http:// bit.ly/2TE0gZa. Acesso em 20/08/2019.

ZOURABICHVILI, F. O vocabulário de Deleuze. Tradução de André Telles. Rio de Janeiro, 2004.

Recebido em 20/8/2019 Aceito em 11/11/2019 